\title{
Pemisahan Hidrokarbon dalam Limbah Katalis Asam (Spent Acid) Proses Alkilasi Olefin dan Isoparafin dengan Proses Presipitasi
}

\author{
Elda Melwita ${ }^{\mathrm{a}, 1, *}$, Syukron Habibie ${ }^{\mathrm{a}, 2}$, Abdul Apandia ${ }^{\mathrm{a}, 3}$ \\ a Jurusan Teknik Kimia, Fakultas Teknik, Universitas Sriwijaya, Jalan Palembang-Pabumulih km. 32 Inderalaya, Ogan Ilir, Sumatera Selatan \\ 1 eldamelwita@ft.unsri.ac.id* \\ * corresponding author
}

\section{ARTICLE INFO}

Article history

Received November 08, 2019

Revised December 16, 2019

Accepted December 17, 2019

Keywords

Spent acid

ASO

Precipitation

Neutralization

Antisolvent

\section{ABSTRACT}

Alkylation of olefin and isoparaffin produces spent acid waste containing high concentration of hydrocarbon. The content of sulphuric acid and hydrocarbon in spent acid put this waste into hazardous waste classification, therefore must be treated to avoid environmental pollution. Hydrocarbon separation can be carried out using precipitation. Two precipitation methods were applied to precipitate hydrocarbon, namely neutralization, and antisolvent precipitation. Neutralization was conducted using $\mathrm{NaOH}, \mathrm{CaCO}_{3}$, and $\mathrm{CaO}$. Meanwhile, antisolvent precipitation was performed using water. Precipitation of hydrocarbon using $\mathrm{CaCO}_{3}$ and $\mathrm{CaO}$ showed very satisfying results. On the other hand, $\mathrm{NaOH}$ was failed to precipitate hydrocarbon. Hydrocarbon was also precipitated using water as antisolvent at ratio of spent acid:water $(\mathrm{g} / \mathrm{ml})$ of 200 .

This is an open access article under the CC-BY-SA license.

\section{Pendahuluan}

Alkilasi adalah reaksi antara olefin dan isoparafin untuk menghasilkan alkilat atau trimetil pentane. Bahan baku olefin terdiri dari propilena, butilena, dan amilena. Sedangkan bahan baku isoparafin yaitu isobutena. Produk alkilat digunakan untuk meningkatkan nilai oktan bahan bakar. Proses alkilasi yang umum digunakan oleh industri perminyakan adalah alkilasi dengan katalis asam sulfat atau asam florida (Tabel 1). Katalis asam yang digunakan memiliki kemurnian $>98 \%$ untuk menghasilkan produk yang baik.

Tabel 1. Perbandingan Produk Alkilasi dengan katalis asam sulfat dan asam florida [1]

\begin{tabular}{ccc}
\hline Komposisi & Alkilat Asam Sulfat (\% vol) & Alkilat Asam Florida (\% vol) \\
\hline Propane & 0,05 & - \\
Isobutene & 0,04 & 0,13 \\
n-butane & 0,92 & 4,87 \\
Isopentane & 8,76 & 5,10 \\
n-pentane & 0,23 & 0,01 \\
C $_{6}$ (total) & 7,29 & 3,69 \\
C7 $_{7}$ (Total) & 30,61 & 40,51 \\
C $_{8}+$ & 52,10 & 45,69 \\
\hline
\end{tabular}

Efisiensi katalis asam akan berkurang karena terjadi proses pembentukan hidrokarbon yang dikenal dengan istilah conjunct polymer atau acid soluble oil (ASO). ASO membentuk kompleks 
dengan asam sehingga akan mengurangi efisiensi asam sebagai katalis. Oleh karena itu, katalis asam yang digunakan harus melalui proses pemurnian untuk mengurangi ASO. Sisa katalis asam yang tidak dapat digunakan menjadi limbah yang disebut spent acid catalyst. Limbah spent acid masih mengandung asam sulfat dengan konsentrasi tinggi (Tabel 2) sehingga tergolong limbah yang berbahaya. Hidrokarbon yang terlarut dalam asam (ASO) memiliki kadar sangat tinggi. Komposisi ASO berdasarkan MSDS ASO yang diterbitkan SASOL (2018) menunjukkan bahwa komposisi utama ASO terdiri dari senyawa-senyawa alkilat dengan kadar asam yang tersisa kurang dari 0,5\% (Tabel 3). Kadar hidrokarbon yang sangat tinggi menyebabkan warna spent acid hitam pekat dengan kekentalan yang sangat tinggi (Gambar 1).

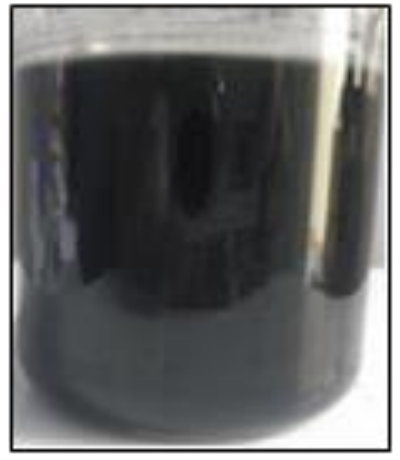

Gambar 1. Spent acid proses alkilasi olefin

Tabel 2. Perbandingan Karakteristik Asam Sulfat Baru dan Spent acid

\begin{tabular}{cccc}
\hline \multirow{2}{*}{ Parameter } & \multirow{2}{*}{ Unit } & \multicolumn{2}{c}{ Nilai } \\
\cline { 3 - 4 } & & Spent acid & Asam Sulfat Baru \\
\hline Appearance & & Dark town & Clear \\
Sulfuric acid & $\% \mathrm{wt}$ & Max 91 & Min 98 \\
$\mathrm{Fe}$ & $\mathrm{Ppm}$ & Max 20 & 100 \\
$\mathrm{~Pb}$ & $\mathrm{Ppm}$ & Max 5 & $<0,1$ \\
$\mathrm{Zn}$ & $\mathrm{Ppm}$ & Max 1 & 0,43 \\
$\mathrm{Cd}$ & $\mathrm{Ppm}$ & Max 1 & - \\
As & Ppm & Max 1 & - \\
Residue & $\% \mathrm{wt}$ & & 4,63 \\
Sediment & $\% \mathrm{wt}$ & & 0,02 \\
\hline
\end{tabular}

Karakterisasi conjunct polymer oleh Miron dkk [2] dan Albright dkk [3] menemukan bahwa polimer terdiri dari hidrokarbon poliolefinik siklik dengan derajat konjugasi heteroanular yang tinggi dimana ikatan rangkap tidak berada pada cincin yang sama. Senyawa-senyawa yang ada dominan memiliki cincin dengan 5 anggota. Karakterisasi ASO oleh Berenblyum dkk [4] mengungkap komposisi ASO yang terdiri dari campuran yang kompleks hidrokarbon jenuh dengan ikatan rangkap terkonjugasi. ASO terbentuk oleh beberapa mekanisme, yaitu interaksi reaktan dengan katalis dan degradasi produk. ASO akan membentuk kompleks yang kuat dengan katalis. ASO yang terbentuk pada proses alkilasi menggunakan asam sulfat atau HF terdiri dari hidrokarbon dengan jumlah atom 19-26. Sementara, proses alkilasi dengan katalis trifluoro metan asam sulfonate menghasilkan ASO dengan jumlah atom hidrokarbon sekitar 56.

Pengolahan spent acid proses alkilasi telah diteliti dengan metode seperti pembakaran, netralisasi, adsorpsi, ekstraksi, polimerisasi, elektrodekomposisi, dan lain-lain (Tabel 4). Saat ini, metode yang umum digunakan di industri adalah metode pembakaran karena dianggap lebih mudah dan ekonomis. Akan tetapi, metode pembakaran akan menghasilkan gas-gas berbahaya hasil pembakaran karbon dan sulfur seperti $\mathrm{CO}, \mathrm{CO}_{2}, \mathrm{SO}_{2}$, dan $\mathrm{SO}_{3}$. Oleh karena itu, pengembangan metode lain yang lebih aman bagi lingkungan sangat diperlukan untuk mengolah spent acid proses alkilasi ini. 
Tabel 3. Komposisi ASO [5]

\begin{tabular}{cc}
\hline Komponen & Kadar (\%) \\
\hline Antrasen (alkilat) & $<40$ \\
Alkana C10-14 & $<18$ \\
Naftalen (alkilat) & $<12$ \\
Indane (alkilat) & $<10$ \\
Fluorene (alkilat) & $<4$ \\
Acenaphtylene (alkilat) & $<3$ \\
Dialin (alkilat) & $<3$ \\
Benzen & $<1$ \\
Asam Florida & $<0,5$ \\
Hidrokarbon aromatic tak terindentifikasi & $<15$ \\
\hline
\end{tabular}

Proses presipitasi banyak digunakan untuk mengolah limbah karena sederhana dan mudah diaplikasikan. Penelitian ini mempelajari karakteristik presipitasi hidrokarbon dalam spent acid dengan metode netralisasi dan metode antisolvent. Metode netralisasi merupakan metode sederhana dan mudah digunakan di industri. Kelebihan metode ini adalah dapat menghilangkan asam sulfat yang terdapat dalam limbah tanpa menghasilkan senyawa-senyawa berbahaya. Metode antisolvent menggunakan air dapat memisahkan hidrokarbon tanpa menggunakan bahan-bahan kimia.

Tabel 4. Metode Pengolahan Spent acid

\begin{tabular}{|c|c|c|}
\hline Peneliti & Referensi & Metode \\
\hline Zhou dkk [6] & $\begin{array}{c}\text { Journal of Cleaner Production Volume 215, } \\
1 \text { April 2019, Pages 13-21 }\end{array}$ & Polimerisasi \\
\hline Chou dkk. [7] & US Patent No. 0369792 A1, Dec. 27, 2018 & Paired oxidation electrolysis \\
\hline Cross dkk. [8] & US Patent No. 8,084,661 B2 Dec. 27, 2011 & Extraction of ASO using liquid $\mathrm{SO}_{2}$ \\
\hline Hommeltoft dkk. [9] & US Patent No. 6,340,414 B1, Jan. 2, 2002 & Acid distillation \\
\hline Chou dkk. [10] & US Patent No. 5,547,655, Aug. 20, 1996 & Electrochemical process \\
\hline Jalkian dkk. [11] & US Patent No. 5,304,522, April 19, 1994 & $\begin{array}{l}\text { Adsorption using macroporous } \\
\text { polymer }\end{array}$ \\
\hline Kutney dkk. [12] & US Patent No. 5,080,756, Jan. 4, 1992 & Kraft Pulping Process \\
\hline Wiewierowski dkk. [13] & US Patent No. 5,114,699, May. 19, 1992 & Polymerization \\
\hline Sung dkk. [14] & 1993, 32 (11), pp 2490-249 & Decomposition of sulfuric acid \\
\hline
\end{tabular}

\section{Metode Penelitian}

\subsection{Bahan Penelitian}

Bahan utama penelitian adalah spent acid proses alkilasi olefin yang diperoleh dari PT. Pertamina RU III Plaju, $\mathrm{NaOH}$ teknis, $\mathrm{CaCO}_{3}$ teknis, $\mathrm{CaO}$ teknis, dan aquades.

\subsection{Prosedur Penelitian}

\section{1) Analisa bahan baku}

Parameter spent acid yang perlu diketahui adalah kadar asam sulfat yang dianalisa dengan titrasi menggunakan basa.

\section{2) Proses presipitasi hidrokarbon dengan metode netralisasi}

Netralisasi dilakukan dengan menggunakan $\mathrm{NaOH}, \mathrm{CaCO}_{3}$, dan $\mathrm{CaO}$. Padatan dihaluskan dan diayak dengan ayakan 100 mesh. Sementara, spent acid diencerkan dengan air untuk menurunkan viskositas. Bahan-bahan ditimbang dengan rasio tertentu, kemudian dimasukkan ke dalam reaktor gelas dan direaksikan hingga $\mathrm{pH}$ netral. Hasil reaksi didiamkan untuk memisahkan padatan.

\section{3) Proses presipitasi hidrokarbon dengan metode anti solven air}

Spent acid ditimbang sebanyak 5 gram, lalu dicampur dengan air menurut rasio spent acid:air (g/ml) 10, 20, 40, 50, 100, dan 200. Campuran diaduk hingga homogen, kemudian didiamkan untuk memisahkan padatan. 
4) Analisa $\mathrm{pH}$

Pengukuran $\mathrm{pH}$ dilakukan dengan $\mathrm{pH}$ meter dan kertas indikator $\mathrm{pH}$.

\section{Hasil dan Pembahasan}

\subsection{Karakteristik Proses Presipitasi dengan $\mathrm{NaOH}$}

Netralisasi spent acid dengan $\mathrm{NaOH}$ berlangsung menurut reaksi:

$$
2 \mathrm{NaOH}(\mathrm{p})+\mathrm{H}_{2} \mathrm{SO}_{4}(\mathrm{aq}) \longrightarrow \mathrm{Na}_{2} \mathrm{SO}_{4}(\mathrm{aq})+\mathrm{H}_{2} \mathrm{O}(\mathrm{l})
$$

Produk reaksi yang dihasilkan adalah natrium sulfat yang larut dalam air. Pengendapan padatan sangat lambat karena dispersifitas hidrokarbon sangat tinggi dalam cairan sehingga menghambat pemisahan padatan dari cairan (Gambar 2a). Di samping itu, kelarutan $\mathrm{NaOH}$ dalam cairan menyebabkan produk memiliki $\mathrm{pH}$ basa jika terjadi kelebihan pemakaian $\mathrm{NaOH}$. Karakteristik ini menyebabkan netralisasi spent acid dengan $\mathrm{NaOH}$ tidak memberikan manfaat dalam pengolahan spent acid.

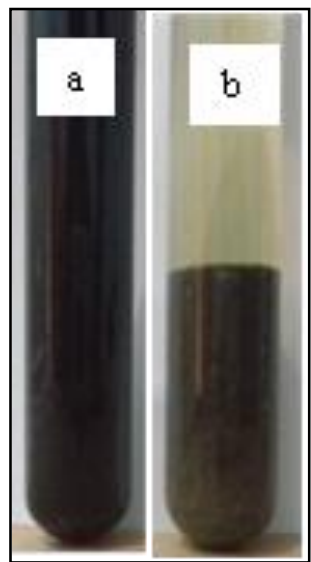

Gambar 2. Karakteristik pemisahan padatan hasil netralisasi (a) menggunakan $\mathrm{NaOH}$ (b) menggunakan $\mathrm{CaCO}_{3}$

\subsection{Karakteristik Proses Proses Presipitasi dengan $\mathrm{CaCO}_{3}$}

Spent acid dan $\mathrm{CaCO}_{3}$ bereaksi melalui mekanisme sebagai berikut:

$$
\mathrm{CaCO}_{3}(\mathrm{p})+\mathrm{H}_{2} \mathrm{SO}_{4}(\mathrm{aq}) \longrightarrow \mathrm{H}_{2} \mathrm{O}+\mathrm{CO}_{2}(\mathrm{~g})+\mathrm{CaSO}_{4}(\mathrm{p})
$$

Produk reaksi netralisasi dengan $\mathrm{CaCO}_{3}$ adalah $\mathrm{CaSO}_{4}$ yang berbentuk padat. Padatan yang terbentuk dapat menyebabkan hidrokarbon mengendap bersama sehingga terpisah dari fasa cair. Selain itu, proses netralisasi dengan $\mathrm{CaCO}_{3}$ menghasilkan cairan dengan $\mathrm{pH}$ netral meskipun menggunakan rasio $\mathrm{CaCO}_{3}$ yang berlebihan karena kelarutan $\mathrm{CaCO}_{3}$ dalam air sangat rendah. Reaksi netralisasi spent acid dengan $\mathrm{CaCO}_{3}$ melepaskan gas $\mathrm{CO}_{2}$ sehingga reaktor harus menggunakan ventilasi untuk mengeluarkan $\mathrm{CO}_{2}$. Kekentalan spent acid sangat mempengaruhi perpindahan masa dalam reaksi netralisasi dengan $\mathrm{CaCO}_{3}$. Spent acid dengan pengenceran hingga rasio 1:15 $(\mathrm{g} / \mathrm{ml})$ menghasilkan produk yang sangat kental sehingga tidak terjadi pemisahan padatan dan cairan (Gambar 3). Pemisahan terjadi pada pemakaian spent acid dengan rasio pengenceran diatas 1:20 (g/ml). Rasio pengenceran yang semakin tinggi akan menghasilkan pemisahan padatan dan cairan yang semakin cepat.

\subsection{Karakteristik Proses Netralisasi dengan $\mathrm{CaO}$}

Reaksi antara $\mathrm{CaO}$ dan spent acid berlangsung menurut persamaan:

$$
\mathrm{CaO}(\mathrm{p})+\mathrm{H}_{2} \mathrm{SO}_{4}(\mathrm{aq}) \longrightarrow \mathrm{CaSO}_{4}(\mathrm{p})+\mathrm{H}_{2} \mathrm{O}
$$

Produk reaksi adalah padatan $\mathrm{CaSO}_{4}$ yang mengendap bersama dengan hidrokarbon dalam waktu singkat. Kelebihan pemakaian $\mathrm{CaO}$ adalah tidak menghasilkan gas $\mathrm{CO}_{2}$. Namun, kelarutan $\mathrm{CaO}$ yang cukup tinggi dapat menyebabkan $\mathrm{pH}$ cairan sisa menjadi basa jika pemakaian $\mathrm{CaO}$ berlebih. Jumlah $\mathrm{CaO}$ yang diperlukan mesti dihitung dengan teliti untuk menghindari kenaikan $\mathrm{pH}$ cairan. 


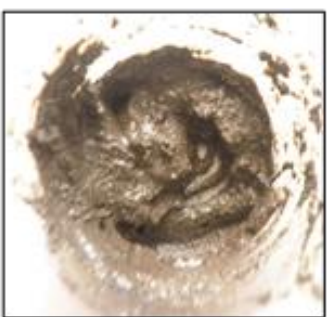

Gambar 3. Produk netralisasi spent acid dengan $\mathrm{CaCO}_{3}$ dan $\mathrm{CaO}$ dengan rasio pengenceran 1:15 (g/ml)

\subsection{Karakteristik Presipitasi dengan Anti Solven Air}

Presipitasi hidrokarbon dengan penambahan air terjadi karena kelarutan hidrokarbon dalam asam berkurang. Air akan mengikat asam sulfat sehingga mengurangi gaya tarik cairan terhadap hidrokarbon. Pengaruh penambahan air terhadap presipitasi hidrokarbon pada rasio spent acid:air $(\mathrm{g} / \mathrm{ml})$ 1:50, 1:100, dan 1:200 terlihat pada Gambar 4. Penambahan air hingga rasio spent acid:air $(\mathrm{g} / \mathrm{ml})$ 1:50 (Gambar 4.a) menunjukkan hidrokarbon masih banyak yang terlarut sehingga warna cairan coklat gelap. Peningkatan jumlah air mengurangi kelarutan hidrokarbon, sehingga pada rasio spent acid:air (g/ml) 1:200 (Gambar 4.c) menghasilkan cairan jernih kecoklatan. Namun, penambahan air tidak dapat mengendapkan semua hidrokarbon sehingga cairan masih coklat.

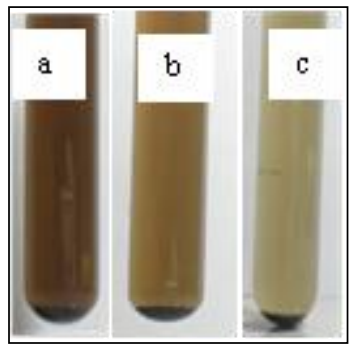

Gambar 4. Prespitasi hidrokarbon dengan metode anti solven pada rasio spent acid:air (g/ml)

(a) 1:50 (b) 1:100 (c) 1:200

\section{Kesimpulan}

Pemisahan hidrokarbon dari spent acid dengan metode presipitasi dapat dilakukan dengan metode netralisasi dan antisolvent. Presipitasi dengan netralisasi akan menghilangkan asam sulfat. Produk yang dihasilkan adalah hidrokarbon yang bercampur dengan $\mathrm{CaSO}_{4}$ dan cairan netral jika menggunakan netralisasi menggunakan $\mathrm{CaCO}_{3}$ dan $\mathrm{CaO}$. Netralisasi dengan $\mathrm{NaOH}$ tidak memberikan manfaat dalam hal produk reaksi. Sementara, presipitasi dengan metode anti solven air dengan rasio spent acid:air $(\mathrm{g} / \mathrm{mL})$ 1:200 menghasilkan padatan hidrokarbon dan cairan asam sulfat dengan sedikit hidrokarbon terlarut.

\section{Ucapan Terima Kasih}

Terima kasih kepada PT. Pertamina RU III yang telah memberikan izin untuk penelitian pengolahan limbah spent acid.

\section{Daftar Pustaka}

[1] S. Singhal, S. Agarwal, S. Arora, N. Singhal, dan A. Kumar, "Solid acids: potential catalysts for alkeneisoalkane alkylation", Catal. Sci. Technol, vol.7, pp. 5810-5819, 2017.

[2] S. Miron and R. Lee,"Molecular Structure of Conjunct Polymers" J. Chem. Eng. Data, vol. 8 (1), pp. $150-160,1963$.

[3] L.F. Albright, M.A. Spalding, C.G. Kopser, dan R.E. Eckert,"Alkylation of isobutane with C4 olefins. 2. Production and characterization of conjunct polymers", Ind. Eng. Chem. Res., vol. 27 (3)pp. 386-391, 1988.

[4] A.S. Berenblyum, L.V.Ovsyannikova, E.A. Katsman, J. Zavilla, S.I. Hommeltoft, dan Yu.Z. Karasev, "Acid soluble oil, by-product formed in isobutane alkylation with alkene in the presence of trifluoro 
methane sulfonic acid: Part I Acid soluble oil composition and its poisoning effect", Applied Catalysis A: General, vol. 232. Issues 1-2, pp. 51-58, 2002.

[5] SASOL, Acid soluble oil (ASO) MSDS, 2018.

[6] Z. Zhou, X. Zhang, F. Yang, dan S. Zhang, "Polymeric carbon material from waste sulfuric acid of alkylation and its application in biodiesel production", Journal of Cleaner Production, Volume 215 (1), pp. 13-21, 2019.

[7] C.S. Chou, dkk, "Method of Regeneration of a Spent Sulfuric Acid Catalyst from Alkylation of Olefins and Alkanes via Paired Oxidation”, US Patent No. 0369792, United States, 2018.

[8] W.M. Cross, dkk., "Extraction of ASO from Spent Sulphuric Acid using Liquid SO2", US Patent No. 8,084,661, United States, 2011.

[9] S.I. Hommeltoft dkk., " Process for The Recovery of Perfluorinated Sulphonic acids from Spent Acid", US Patent No. 6,340,414 B1, United States, 2002.

[10]T.C. Chou dkk., "Recovery and Regeneration of Sulfuric Acid, US Patent No. 5,547,655, United States, 1996.

[11]R. Jalkian dkk., "Liquid Acid Regeneration Method", US Patent No. 5,304,522, United States, 1994.

[12] G.W. Kutney dkk., "Sulphuric Acid Addition to Strong Black Liquor", US Patent No. 5,080,756, United States, 1992.

[13]T.K. Wiewierowski dkk., "Spent Alkylation Acid Treatment Process", US Patent No. 5,114,699, United States, 1992.

[14]S. Sung dkk., "Decomposition of spent alkylation sulfuric acid to produce sulfur dioxide and water", Ind. Eng. Chem. Res., vol. 32 (11), pp. 2490-249, 1993. 